\title{
Analisis Distribusi Pasar dan Margin Pemasaran Gabah - Beras dalam Ketahanan Pangan di Bali
}

\author{
Analysis of Market Distribution and Marketing Margin of Grain - Rice \\ in Food Security in Bali
}

\author{
Made Adi Wahyuni*) \\ Ketut Kariada \\ A.A. Istri Mas Darmawati \\ Dinas Ketahanan Pangan Provinsi Bali, Indonesia \\ ${ }^{*}$ Email : madeadiwahyuni21@gmail.com
}

\begin{abstract}
Food Security is the condition of fulfilling food for the state to individuals, which is reflected in the availability of sufficient food, both in quantity and quality, safe, diverse, nutritious, equitable and affordable and does not conflict with religion, belief, and culture of the community, in order to be able to live. healthy, active, and productive in a sustainable manner. This study aims to: (i) describe the performance of the grain/rice marketing flow from farmers (producers) to final consumers, (ii) analyze cost components, and the amount of marketing margin for each marketing actor, ( iii) calculate and the highest level of efficiency in marketing distribution channels, and (iv) identify problems in rice marketing margins. The research was conducted in 2021 in Bali Province from MayJuly 2021. This research is descriptive in nature using the Participatory Rural Appraisal (PRA) method with a Snow Ball Sampling approach as a starting point. The results of the study found 2 (two) distribution channels of unhulled rice/rice marketing in the province of Bali. (80\%) I (First), 20\% to II (Second), rice in Channel I (First), the highest margin is obtained by Milling/RMU business actors, amounting to Rp.435.475/Kg Rice (34.22\%), followed by Wholesalers (Wholesale Traders) Rp. 393/Kg Rice (30.81\%), Retail Traders Rp. 320/Kg (25.15\%) followed by Slasher/Gathering Trader Rp.125/Kg Rice (9.82\%). While the Marketing Margin for Channel II (Second), the highest margin is obtained by Gapoktan/Milling/RMU (Wholesale Traders) business actors, amounting to Rp. 234/Kg Rice (53.90\%), followed by PMT/TTIC/TTI (Retail Traders) Rp. 200/Kg Rice (46.10\%). From the analysis of the level of marketing efficiency, distribution channel I (first) is more efficient than channel II (two).
\end{abstract}

Keywords: Market and efficiency. 


\begin{abstract}
ABSTRAK
Ketahanan Pangan adalah kondisi terpenuhinya pangan bagi negara sampai dengan perseorangan, yang tercermin dari tersedianya pangan yang cukup, baik jumlah maupun mutunya, aman, beragam, bergizi, merata, dan terjangkau serta tidak bertentangan dengan agama, keyakinan, dan budaya masyarakat, untuk dapat hidup sehat, aktif, dan produktif secara berkelanjutan Penelitian ini bertujuan untuk : (i) menggambarkan keragaan alur pemasaran gabah/beras mulai dari petani (produsen) sampai konsumen akhir, (ii) menganalisis komponen biaya, dan besarnya margin pemasaran pada setiap pelaku pemasaran, (iii) menghitungdan tingkat efisiensi tertinggi dalam saluran distribusi pemasaran, dan (iv) mengidentifikasi permasalahan pada margin pemasaran beras. Penelitian dilaksanakan Tahun 2021 di Propinsi Bali dari Bulan Mei - Juli 2021. Penelitian ini bersifat deskriptip menggunakan metoda Participatory Rural Appraisal (PRA) dengan pendekatan Snow Ball Sampling sebagai titik awal (starting point). Hasil Penelitian ditemukan 2 (dua) aliran distribusi pemasaran Gabah/Beras di Proviunsi Bali. (80 \%) I (Pertama), $20 \%$ ke II (Kedua), beras pada Saluran I (Pertama), margin tertinggi diperoleh pelaku usaha Penggilingan/RMU, sebesar Rp.435,475/Kg Beras (34,22\%), disusul oleh Pedagang Besar (Pedagang Grosir) sebesar Rp. 393/Kg Beras (30,81\%), Pedagang Eceran sebesar Rp. 320/Kg (25,15 \%) disusul pada Penebas/Pedagang Pengumpul Rp.125/Kg Beras $(9,82 \%)$. Sedangkan Margin Pemasaran Saluran II (Kedua), margin tertinggi diperoleh pelaku usaha Gapoktan/Penggilingan/RMU (Pedagang Grosir), sebesar Rp. 234/Kg Beras (53,90\%), disusul oleh PMT/TTIC/TTI (Pedagang Eceran) sebesar Rp. 200/Kg Beras (46,10\%). Dari hasil analisa tingkat efisiensi pemasaran, maka saluran distribusi I (pertama) lebih efisien dibandingkan dengan saluran ke II (dua).
\end{abstract}

Kata kunci : Pasar dan Efisiensi.

\title{
PENDAHULUAN
}

Pergub Nomor 7 Tahun 2019 tentang Struktur Organisasi Ketersediaan Distribusi Cadangan merupakan bagian dari pelaksanaan pembangunan pertanian dalam arti luas dalam hal distribusi dan harga pangan dan diharapkan juga dapat memberikan kontribusi positif dalam mencapai visi Pembangunan Bali Tahun 2018 - 2023 yaitu Nangun Sat Kerthi Loka Bali melalui Pola Pembangunan Semesta Berencana menuju Bali Era Baru.

Pangan sering diidentikkan beras karena ini membuktikan kepada kita dapat menjadi multidemensi membahayakan. Bagi penduduk Indonesia, beras merupakan bahan makanan yang sangat pokok daripada bahan makanan yang lainnya seperti jagung, sagu, ubi, dan bahan pangan lainnya, sehingga masyarakat yang berpendapatan rendah sangat berupaya semaksimal mungkin untuk memenuhi kebutuhan pangan pokoknya, termasuk beras. Oleh karena itu, beras sangat menunjang tingkat kesejahteraan masyarakat (Aji dan Widodo, 2010)

Indonesia tercatat dengan jumlah penduduk yang mengonsumsi beras terbesar. Pada tahun 2020 konsumsi beras perkapita di Indonesia 92,9 per kilogram (beras, per orang, pertahun). 
Hal tersebut akan berdampak pada permintaan beras di pasar. Pembentukan harga akan dipengaruhi oleh pelaku pasar. Para pelaku pasar sendiri mempunyai pola atau saluran distribusi pemasaran. Ariwibowo (2013) mengatakan bahwa pola atau saluran beras mempunyai tahapan sebagai berikut, yaitu petani melakukan proses panen, lalu menjual gabah ke penggilingan gabah, dari penggilingan gabah akan diolah menjadi beras sehingga akan dipasarkan ke konsumen. Komoditas beras merupakan komiditas penting karena perannya sebagai makanan pokok yang setiap penduduk Indonesia mengkonsumsinya setiap hari sebagai asupan karbohidrat. Beras juga merupakan komoditas strategis yang dominan dalam ekonomi Indonesia karena berkaitan dengan kebijakan moneter dan menyangkut masalah sosial (Adiratma, 2004).

Daerah sentra produksi padi di Bali meliputi : Kabupaten Tabanan, Gianyar, Badung, Buleleng dan Jembrana. Secara rinci, penelitian bertujuan untuk :(i) menggambarkan keragaan alur pemasaran gabah/beras mulai dari petani (produsen) sampai konsumen akhir, (ii) menganalisis komponen biaya, dan besarnya margin pemasaran pada setiap pelaku pemasaran, (iii) menghitungdan tingkat efisiensi tertinggi dalam saluran distribusi pemasaran, dan (iv) mengidentifikasi permasalahan pada margin pemasaran beras. Hasil penelitian diharapkan menjadi bahan kebijakan dalam perbaikan sistem pemasaran gabah/beras nasional terutama di Propinsi Bali.

\section{METODOLOGI PENELITIAN}

Penelitian dilaksanakan Tahun 2021 di Propinsi Bali dari Bulan Mei - Juli 2021. Daerah sentra beras di Provinsi Bali. Pelaksanaan penelitian dilaksanakan. Penelitian ini bersifat deskriptip menggunakan metoda Participatory Rural Appraisal (PRA) dengan pendekatan Snow Ball Sampling dimana petani sebagai titik awal (starting point). Data primer dikumpulkan dari 70 petani, 21 pedagang, 7 penggilingan padi, dan 21 konsomen akhir. Data sekunder dikumpulkan dari Dinas Pertanian dan Ketahanan Pangan dan Dinas/Instansi terkait lain.

Data yang didapatkan di lapangan akan ditabulasi dengan alat uji yaitu :

1. Identifikasi masalah akan diuji dengan analisis deskriptif berdasarkan survey di Daerah Penelitian

2. Dalam menghitung Margin pemasaran beras, dihitung dengan rumus matematis (Masyrofi, 1994) :

$$
\mathrm{MP}=\mathrm{Pr}-\mathrm{Pf}
$$

Dimana : $\operatorname{Pr}=$ Harga eceran atau harga di tingkat konsumen

Pf $=$ harga di tingkat petani produsen

MP ini hanya menggambarkan perbedaan harga dan tidak mempersoalkan jumlah produk yang dipasarkan.

Share biaya MP ke-i dan Jenis Biaya Pemasaran ke-i : Sbi = (bi/MP) x 100\%, Bagian harga yang diterima oleh petani dari harga yang dibayarkan oleh konsumen terakhir adalah :

$$
\mathrm{Y}=100 \%-(\mathrm{MP} / \mathrm{Pf}) \times 100 \% \text {. }
$$


Selanjutnya akah dihitung harga yang dibayarkan oleh konsumen terakhir terhadap harga yang diterima oleh petani :

$$
\mathrm{Q}=100 \%+(\mathrm{MP} / \mathrm{Pf}) \times 100 \% \text { atau } \mathrm{Q}=(\mathrm{Pf} / \mathrm{Pr}) \times 100 \% \text {. }
$$

Rasionalitas dapat diketahui dengan mebandingkan antara tingkat keuntungan dengan biaya yang dikeluarkan oleh lembaga pemasaran selama proses transaksi jual beli beras berlangsung ( Rasio $=\pi /$ Sbi $)$.

3. Saluran pemasaran yang mana memiliki tingkat efisiensi tertinggi, maka digunakan analisis matematis dengan rumus sebagai berikut :

Tingkat efisiensi tertinggi, maka digunakan analisis matematis dengan rumus sebagai berikut :

$$
\mathrm{Ep}=\frac{\text { Biaya Pemasaran }(\mathrm{Rp} / \mathrm{Kg})}{\text { Harga Jual }(\mathrm{Rp} / \mathrm{Kg})}
$$

Kriteria pengambilan keputusan :

- EP sebesar 0 - 50\% maka saluran pemasaran efisien.

- EP lebih besar dari 50\% maka saluran pemasaran kurang efisien.

\section{HASIL DAN PEMBAHASAN}

Pelaksanaan kegiatan Analisis Distribusi Pasar dan Margin Pemasaran Gabah - Beras dalam Ketahanan Pangan di Bali, dilaksanakan mulai Bulan Mei - Juli 2021 seiring dengan pelaksanaan pengumpulan data informasi harga oleh petugas Enumerator. Lokasi pelaksanaan kegiatan meliputi daerah sentra padi terluas di Bali.

Sistem distribusi produksi pangan dari produsen sampai ke konsumen terdiri dari berbagai tingkat (mata rantai) mulai dari produsen, pedagang pengumpul di tingkat desa/kecamatan/ kabupaten, pedagang grosir sampai kepada pedagang pengecer di tingkat konsumen. Dari masing-masing pelaku tersebut akan memperoleh keuntungan/margin yang berbeda-beda, tergantung pada masing-masing pelaku pasar, posisi tawar serta efisiensi usaha masingmasing pelaku pasar tersebut. Dari beberapa survey didapat bahwa terjadi ketimpangan distribusi margin antara sub sistem “on farm" dengan sub sistem "off farm”, dimana distribusi margin terbesar justru diperoleh pada sub sistem distribusi dan pemasaran. Fakta menunjukkan bahwa margin pada sub sistem budidaya (produksi) hanya 9\%, sangat kecil dibandingkan dengan margin di sub sistem pasca panen \& pengolahan yang mencapai $17 \%$ serta margin sub sistem pemasaran yang mancapai $62 \%$.

Berdasarkan atas hasil pengumpulan dan analisa data distribusi, margin pemasaran dan efisiensi pemasaran beras di Bali, diperoleh hasil sebagai berikut :

\section{Saluran Distribusi Pasar Gabah/Beras}

Berdasarkan atas hasil pemantauan di lapangan terhadap para pelaku pasar yang terlibat dalam distribusi bahan pangan beras di Bali, diperoleh 2 (dua) saluran distribusi pasar sebagai berikut :

Saluran distribusi gabah/beras antar wilayah, pada saluran I (pertama) nampak terjadinya aliran produk dari daerah sentra produksi ke wilayah non sentra produksi, gabah pedagang 
besar (pedagang grosir) dengan beras yang sudah dikemas dan berlabel untuk selanjutnya seperti Gambar 1 dibawah ini.

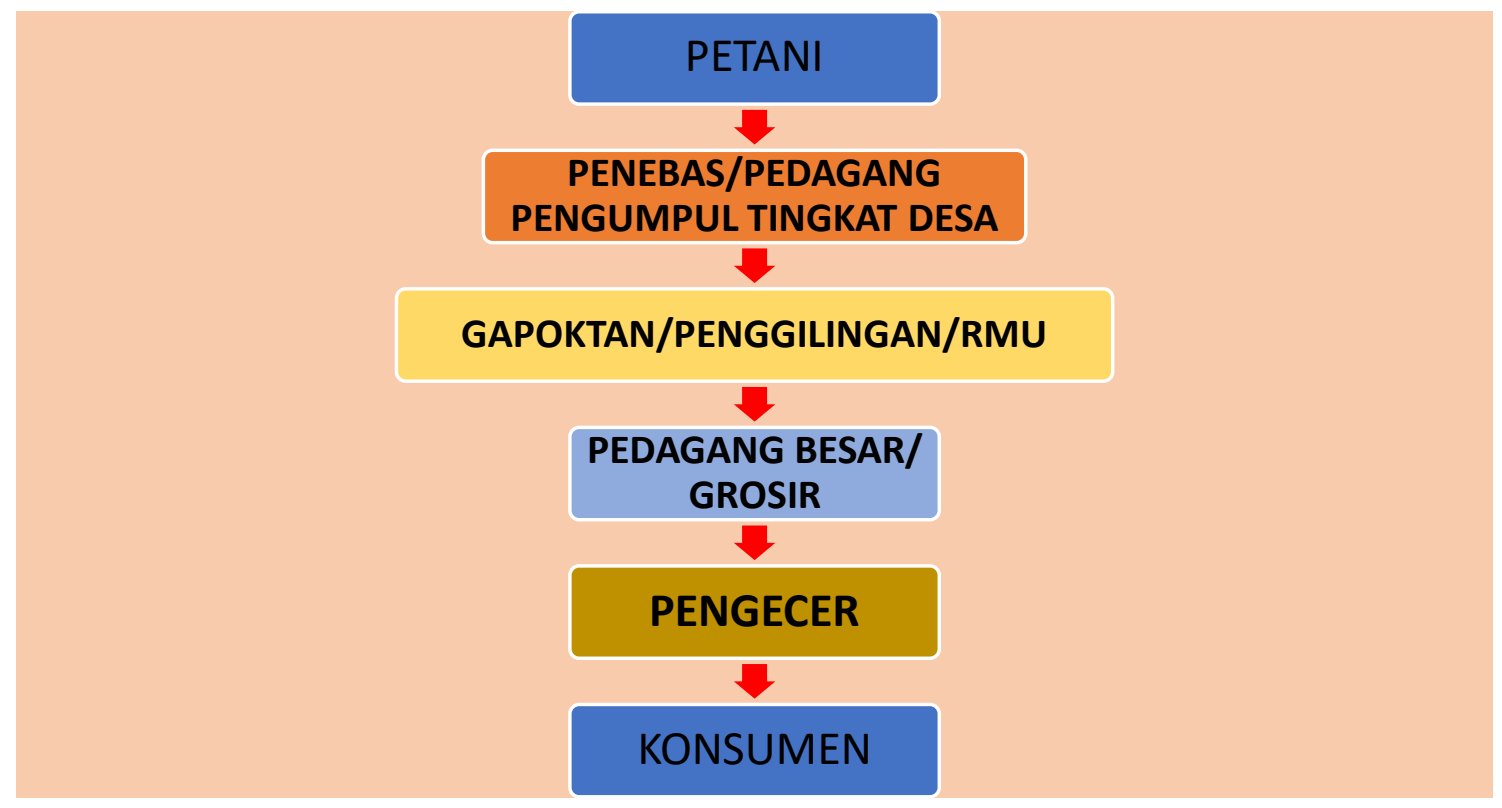

Gambar 1. Saluran I Distribusi Pasar Gabah/Beras

Dari Gambar tersebut diatas, dapat dikatakan bahwa sistem ketahanan pangan terdiri atas 3 sub sistem utama, yaitu: sub sistem produksi dan ketersediaan, sub sistem distribusi dan sub sistem konsumsi. Selama ini kegiatan di bidang sub sistem produksi dan ketersediaan pangan beras telah banyak dilakukan dalam upaya menyediakan bahan pangan yang cukup dari segi kuantitas maupun mutu melalui kegiatan pengembangan teknik bididaya. Untuk dapat sampai pada sub sistem konsumsi, maka sub sistem distribusi petani penebas/pedagang pengumpul tingkat desa - penggilingan/RMU - pedagang besar/grosirpedagang pengecer memiliki peran yang sangat penting dalam upaya menghubungkan antara produsen dengan konsumen sekaligus mengatur atau memfasilitasi agar komoditi dapat disalurkan dari daerah produsen/sentra produski sampai kelokasi dimana komoditi pangan tersebut dapat dikonsumsi oleh konsumen. Dalam sub sistem distribusi juga dimungkinkan adanya peningkatan pendapatan/nilai tambah, berkaitan dengan ketepatan waktu, baik mutu/kualitas dan kuantitas pangan (beras).

Selanjutnya saluran distribusi gabah/beras antar wilayah, pada saluran II (dua) nampak terjadinya aliran produk dari daerah sentra produksi ke wilayah non sentra produksi, dengan adanya sistem subsidi dari pemerintah. Saluran distribusi gabah Gapoktan PMT/TTIC (pedagang eceran) dengan beras yang sudah dikemas dan berlabel sesuai daerah asal Gapoktan untuk selanjutnya disalurkan dijual ke konsumen, seperti Gambar 2 dibawah ini. 


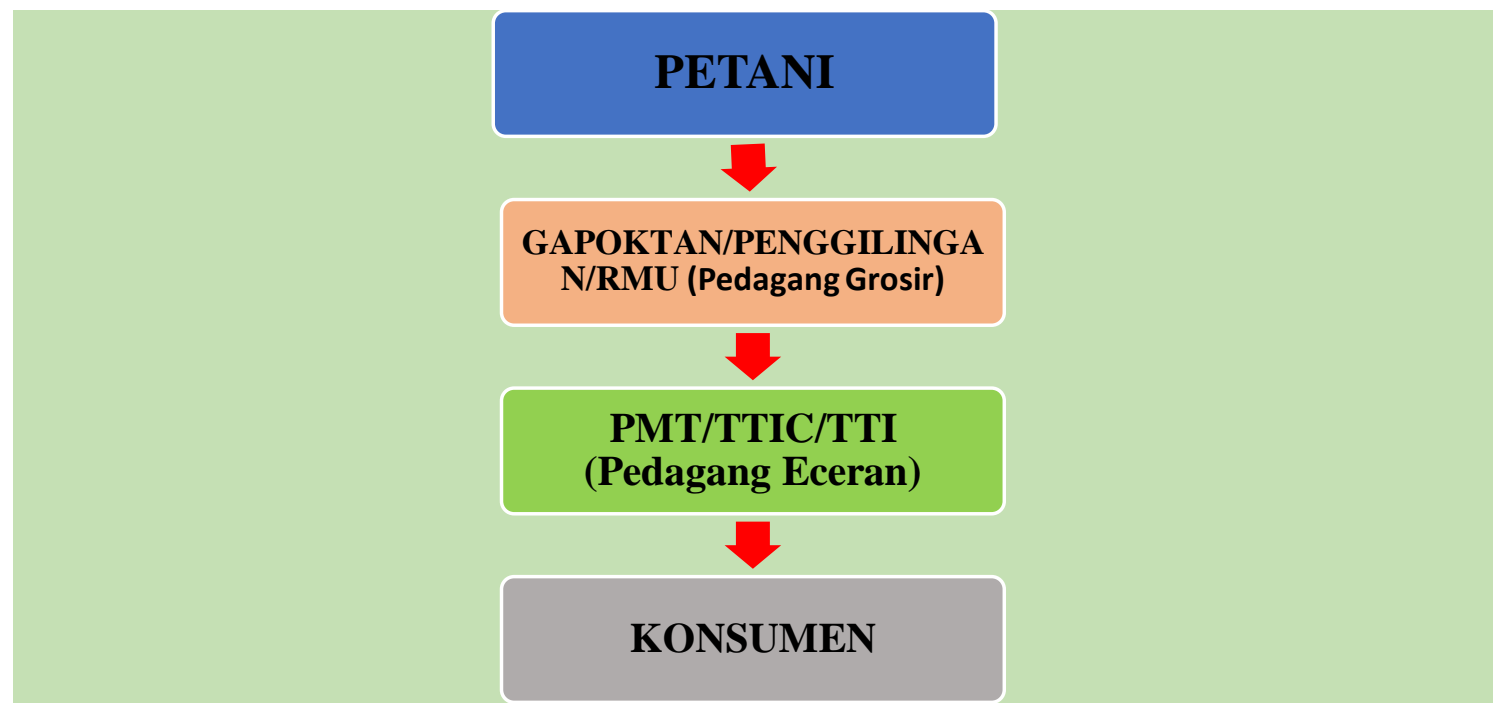

Gambar 2. Saluran II Distribusi Pasar Gabah/Beras

Pada Gambar dapat dikatakan bahwa sistem ketahanan pangan terdiri atas 3 sub sistem utama, yaitu : sub sistem produksi dan ketersediaan, sub sistem distribusi dan sub sistem konsumsi. Selama ini kegiatan di bidang sub sistem produksi dan ketersediaan pangan beras telah banyak dilakukan dalam upaya menyediakan bahan pangan yang cukup dari segi kuantitas maupun mutu melalui kegiatan pengembangan teknik bididaya. Untuk dapat sampai pada sub sistem konsumsi, maka sub sistem distribusi petani Gapoktan/penggilingan/RMU (pedagang grosir) - PMT/TTIC/TTI (pedagang pengecer) memiliki peran yang sangat penting dalam upaya menghubungkan antara produsen dengan konsumen sekaligus mengatur atau memfasilitasi agar komoditi dapat disalurkan dari daerah produsen/sentra produski sampai ke lokasi dimana komoditi pangan tersebut dapat dikonsumsi oleh konsumen. Dalam sub sistem distribusi juga dimungkinkan adanya peningkatan pendapatan/nilai tambah, berkaitan dengan ketepatan waktu, baik mutu/kualitas dan kuantitas pangan (beras).

\section{Analisis Biaya dan Margin Pemasaran}

Margin pemasaran ialah selisih harga yang dibayarkan oleh konsumen dan harga yang diterima oleh petani (Rp) dan merupakan salah satu indikator yang digunakan untuk mengukur tingkat efisiensi suatu sistem pemasaran (Aroning, 2008). Margin Pemasaran terdiri dari biaya pemasaran dan keuntungan lembaga pemasaran. Dari 2021, di masingmasing pelaku pemasaran secara umum (saluran I) sebagaimana tercantum pada Tabel 1. 
Tabel 1. Margin Pemasaran Gabah/Beras di Provinsi Bali 2021.

\begin{tabular}{|c|c|c|c|c|}
\hline No & Pelaku Pasar & $\begin{array}{c}\text { Harga } \\
(\mathrm{Rp} / \mathrm{Kg})\end{array}$ & $\begin{array}{l}\text { Margin } \\
(\mathrm{Rp} / \mathrm{Kg})\end{array}$ & $\begin{array}{c}\text { Persentase Margin } \\
(\%)\end{array}$ \\
\hline 1 & $\begin{array}{l}\text { Petani /Produsen } \\
\text { a. Gabah GKP }\end{array}$ & 3.600 & $1.380 *)$ & \\
\hline 2 & $\begin{array}{l}\text { Penebas/Pedagang } \\
\text { Pengumpul Tk. Desa } \\
\text { b. Gabah GKP }\end{array}$ & 4.200 & 600 & 9,38 \\
\hline 3 & $\begin{array}{l}\text { Penggilingan/RMU } \\
\text { c. Beras }\end{array}$ & 8.900 & 4.700 & 73,44 \\
\hline 4 & $\begin{array}{l}\text { Pedagang Besar } \\
\text { (Pedagang Grosir) } \\
\text { d. Beras }\end{array}$ & 9.400 & 500 & 7,81 \\
\hline 5 & $\begin{array}{l}\text { Pedagang Eceran } \\
\text { e. Beras }\end{array}$ & 10.000 & 600 & 9,38 \\
\hline 6 & $\begin{array}{l}\text { Konsumen } \\
\text { f. Beras }\end{array}$ & 10.000 & & \\
\hline
\end{tabular}

Dari Tabel diatas diperoleh Rp. 1.380 seperti pada Tabel 2. Pada Tabel 1 dan 2 Penggilingan/RMU, sebesar Rp. 435,47 /Kg beras (34,22\%), pedagang besar (grosir) sebesar Rp. 392,00 /kg gabah (30,81\%), pedagang eceran sebesar Rp. 320 (25,15\%) dan nilai terendah diperoleh pedagang pengumpul tingkat desa sebesar Rp. 125,00/kg beras $(9,82 \%)$. Dilihat dari harga pemasaran II secara subsidi dari pemerintah tercantum pada Tabel 3.

Pada Saluran II (dua) setiap saluran dari kegiatan distribusi pasar gabah/beras memperoleh subsidi sebesar Rp.1.200/Kg. Adapun biaya-biaya yang subsidi berupa biaya angkut gabah, ongkos bongkar muat gabah, biaya jemur gabah, biaya penyosohan dan penggilingan, ongkos pengemasan beras, biaya kemasan beras, biaya transpoertasi dari Gapoktan/Penggilingan/RMU ke PMT/TTI/TTIC, biaya solar dan biaya bongkar muat beras di PMT/TTI/TTIC. Pada 3.700 Gapoktan/Penggilingan/RMU (Grosir), 234 (53,90\%), PMT/TTIC/ TTI (Eceran) 200 (46,10\%). Margin oleh Gapoktan/Penggilingan $2.500=37.500$ 
Tabel 2. Margin Pemasaran Gabah/Beras Secara Umum 2021 di Bali.

\begin{tabular}{|c|c|c|c|}
\hline No & Pelaku Pasar & Jumlah (Rp/Kg) & $\begin{array}{c}\text { Persentase Margin } \\
(\%)\end{array}$ \\
\hline \multirow[t]{3}{*}{1} & & 3.600 & \\
\hline & - usaha tani & 2.220 & \\
\hline & -Keuntungan usaha tani & 1.380 & \\
\hline \multirow[t]{9}{*}{2} & Pedagang Tingkat Desa & 4.200 & \\
\hline & & 600 & \\
\hline & & 400 & \\
\hline & & 25 & \\
\hline & & 125,00 & 9,82 \\
\hline & Penggilingan/RMU & $8.900,00$ & \\
\hline & Harga jual beras & $7.924,53$ & \\
\hline & Harga pokok gabah jadi beras & & \\
\hline & Rendemen $53 \%$ & 975,47 & \\
\hline \multirow[t]{5}{*}{3} & Margin Kotor & 200 & \\
\hline & & 250 & \\
\hline & & 80 & \\
\hline & & 435,47 & \\
\hline & & 34,22 & \\
\hline \multirow[t]{5}{*}{4} & Pedagang Besar (Pedagang Grosir) & 9.400 & \\
\hline & Margin Kotor & 500 & \\
\hline & -Biaya transportasi & 100 & \\
\hline & & 8 & \\
\hline & & 392,00 & 30,81 \\
\hline \multirow[t]{7}{*}{5} & Pedagang Eceran & $10.000,00$ & \\
\hline & Margin Kotor & 600 & \\
\hline & - Biaya kemas dan kemasan & 80 & \\
\hline & & 100 & \\
\hline & - Biaya transportasi & 100 & \\
\hline & & 8 & \\
\hline & & 320,00 & 25,15 \\
\hline
\end{tabular}


Tabel 3. Margin Secara Subsidi Pemerintah II 2021

\begin{tabular}{|c|c|c|c|c|}
\hline No & Pelaku Pasar & Harga $(\mathrm{Rp} / \mathrm{Kg})$ & $\begin{array}{l}\text { Margin } \\
(\mathrm{Rp} / \mathrm{Kg})\end{array}$ & $\begin{array}{c}\text { Persentase } \\
\text { Margin (\%) }\end{array}$ \\
\hline 1 & a. Gabah GKP/tebasan & 3.700 & $1.480 *$ & \\
\hline 2 & $\begin{array}{l}\text { Gapoktan/Penggilingan } \\
\text { (Pedagang Grosir) } \\
\text { b. Beras } \\
\text { PMT/TTIC/TTI (Pedagang }\end{array}$ & 8.800 & 5.100 & 96,23 \\
\hline 3 & $\begin{array}{l}\text { Eceran) } \\
\text { c. Beras }\end{array}$ & 9.000 & 200 & 3,77 \\
\hline 4 & $\begin{array}{l}\text { Konsumen } \\
\text { d. Beras }\end{array}$ & 9.400 & & \\
\hline
\end{tabular}

Dari Tabel 3 diatas diperoleh Rp. 1,480 seperti pada Tabel 4.

Sistem distribusi petani - penebas/pedagang pengumpul tingkat desa - penggilingan/RMUpedagang besar/grosir- Pedagang Pengecer memiliki peran yang sangat penting dalam upaya menghubungkan antara produsen dengan konsumen sekaligus mengatur atau memfasilitasi agar komoditi dapat disalurkan dari daerah produsen/sentra produski sampai kelokasi dimana komoditi pangan tersebut dapat dikonsumsi oleh konsumen. Dalam sub sistem distribusi juga dimungkinkan adanya peningkatan pendapatan/nilai tambah, berkaitan dengan ketepatan waktu, baik mutu/kualitas dan kuantitas pangan (beras). 
Tabel 4. Subsidi Pemerintah Tahun 2021 di Bali.

\begin{tabular}{|c|c|c|c|}
\hline No & Pelaku Pasar & Jumlah & $(\%)$ \\
\hline \multirow[t]{3}{*}{1} & & 3.700 & \\
\hline & -Biaya usaha tani & 2.220 & \\
\hline & -Keuntungan usaha tani & 1.480 & \\
\hline \multirow[t]{17}{*}{2} & $\begin{array}{l}\text { Gapoktan/Penggilingan (Pedagang } \\
\text { Grosir) }\end{array}$ & & \\
\hline & Harga jual beras & 8.800 & \\
\hline & Harga pokok gabah jadi beras & 6.981 & \\
\hline & Rendemen $53 \%$ & & \\
\hline & Margin Kotor & 1.819 & \\
\hline & Biaya panen & 400 & \\
\hline & Biaya karung gabah & 25 & \\
\hline & Ongkos angkut gabah & 75 & \\
\hline & Biaya transportasi & 75 & \\
\hline & Biaya pengeringan & 200 & \\
\hline & Biaya sosoh dan giling & 250 & \\
\hline & Biaya kemasan beras & 200 & \\
\hline & Biaya transportasi & 150 & \\
\hline & Ongkos angkut beras & 100 & \\
\hline & Ongkos pengemasan & 100 & \\
\hline & Biaya sewa gudang & 10 & \\
\hline & Margin Bersih & 234 & 53,90 \\
\hline \multirow[t]{2}{*}{3} & PMT/TTIC/TTI (Pedagang Eceran) & 9.000 & \\
\hline & Margin Bersih & 200 & 46,10 \\
\hline
\end{tabular}

Sumber : Data Olah, 2021

Keterangan : PMT (Pasar Mitra Tani), TTIC (TokoTani Indonesia Center), TTI (Toko Tani Indonesia).

\section{Efisiensi Pemasaran}

Kepuasan atas harga yang diterima oleh produsen, balas jasa yang diterima oleh para perantara serta terlaksananya peraturan dengan baik yang ditetapkan oleh pemerintah adalah juga merupakan "output" pemasaran. Semua pengorbanan yang berupa tenaga kerja, modal dan terlaksana dalam proses pemasaran adalah "input" pemasaran. Dengan demikian efisiensi pemasaran dapat diukur dari "input-output ratio" (Sudiyono.A, 2004). Pemasaran yang efisien apabila biaya pemasaran lebih rendah dari pada nilai produk yang dipasarkan, semakin rendah biaya pemasaran dari nilai produk yang dipasarkan semakin efisien melaksanakan pemasaran. Untuk melihat saluran distribusi pemasaran yang mana memiliki tingkat efisiensi tertinggi dapat dilihat pada Tabel 5. 
Tabel 5. Tingkat Efisiensi Saluran Distribusi Pemasaran Beras di Provinsi Bali, Tahun 2021

\begin{tabular}{ccccc}
\hline No & Distribusi Pemasaran & $\begin{array}{c}\text { Biaya } \\
\text { Pemasaran } \\
(\mathrm{Rp} / \mathrm{Kg})\end{array}$ & $\begin{array}{c}\text { Harga Jual } \\
(\mathrm{Rp} / \mathrm{Kg})\end{array}$ & $\begin{array}{c}\text { Tingkat } \\
\text { Efisiensi (\%) }\end{array}$ \\
\hline 1 & $\begin{array}{c}\text { Saluran Distribusi I } \\
\text { (Pertama) }\end{array}$ & 1.461 & 10.000 & 14,11 \\
2 & $\begin{array}{c}\text { Saluran Distribusi II } \\
\text { (Kedua) }\end{array}$ & 1.585 & 9.000 & 17,61 \\
\hline
\end{tabular}

Sumber : Data Olah, 2021

Tabel 5 menunjukan bahwa total biaya pada saluran pemasaran pertama lebih rendah dari pada saluran kedua hal ini disebabkan pada saluran pertama tidak ada subsidi dari pemerintah sehingga biaya-biaya yang dikeluarkan lebih kecil. Sedangkan total nilai penjualan pada saluran kedua lebih kecil dari saluran pertama karena pada saluran kedua ditentukan dengan harga gabah yang telah disepakati bersama oleh anggota Gapoktan sehingga beras yang dipasarkan pada saluran kedua harga lebih rendah dari mekanisme pasar dan harga efisinsi dapat dinikmati oleh konsumen. Sedangkan pada saluran pertama sesuai dengan mekanisme perkembangan pasar, sehingga harga lebih tinggi dari saluran kedua, namun masih terjangkau oleh konsumen. Dari tingkat efisiensi saluran pertama lebih efisien dibandingkan dengan saluran kedua.

\section{Permasalahan dan Tindak Lanjut}

Pedagang PMT/TTC masalah dalam ketahanan pangan di Bali. Dari penelitian diatas dapat diidentifikasi permasalahan pelaku pasar sebagai berikut :

1. Penjualan hasil produksi padi/gabah petani secara langsung oleh penebas (penebas memanen langsung padi di sawah) sangat sulit dihindari, hal ini disebabkan oleh beberapa hal yaitu petani mempunyai kebutuhan yang mendesak, dan umumnya tidak memiliki sarana pengeringan, dan penyimpanan yang memadai.

3. Dominannya penjualan padi/gabah secara tebasan oleh petani di Bali menyulitkan dalam perhitungan taksasi produksi, yang berdampak kepada kurang akuratnya perhitungan harga di tingkat konsumen.

4. Alur distribusi kadang-kanag tidak pasti karena sangat terkait dengan kuantitas barang di lapangan.

5. Terjadinya fluktuasi harga yang sangat tinggi, khususnya pada bulan-bulan panen puncak, dimana harga cenderung mengalami penurunan secara drastis.

6. Distribusi gabah/beras di Bali khususnya beras secara umum masih relatif panjang, dimana peran penebas masih sangat dominan. Kondisi ini menyebabkan tingkat keuntungan yang diterima petani menjadi semakin kecil. 
Berdasarkan atas kondisi tersebut, maka dapat diajukan alternatif pemecahan masalah, antara lain : mengaktifkan kembali lumbung pangan

\section{SIMPULAN DAN SARAN}

\section{Simpulan}

Pasar $80 \%$ dan $25 \%$ lanjut RMU sesuai daerah asal dari beras, kemudian lanjut disalurkan/dijual ke PMT/TTIC/TTI dengan penjualan beras dibawah harga pasar. Margin pemasaran pada Saluran I, margin tertinggi diperoleh pelaku usaha penggilingan/RMU, sebesar Rp 435,475/kg beras (34,22\%), disusul oleh pedagang besar (pedagang grosir) sebesar Rp 393/kg beras (30,81\%), Pedagang Eceran sebesar Rp. 320/Kg (25,15\%) disusul pada penebas/pedagang pengumpul Rp 125/kg beras. Sedangkan margin pemasaran saluran II, margin tertinggi diperoleh pelaku usaha Gapoktan/penggilingan/RMU (pedagang grosir), sebesar Rp. 234/kg Beras (53,90\%), disusul oleh PMT/TTIC/TTI (pedagang eceran) sebesar Rp 200/kg beras (46,10\%). Kepuasan atas harga yang diterima oleh produsen, balas jasa serta biaya yang dikeluarkan oleh para perantara serta terlaksananya peraturan dengan baik yang ditetapkan oleh pemerintah dalam saluran distribusi pemasaran dalam penelitian ini adalah saluran distribusi pertama yang memiliki tingkat efisiensi tertinggi sebesar $14,11 \%$.

\section{Saran}

Penelitian ini terkait dengan penentuan kebijakan distribusi pasar dan efisiensi margin pemasaran. Perlulah dilakukan analisis lanjut terkait strategi pemasaran gabah-beras lokal dalam mempertahankan ketahanan pangan dan ketahanan bargaining power di tingkat petani.

\section{DAFTAR PUSTAKA}

Adiratma, ER. 2004. Stop Tanam Padi, Memikirkan Kondisi Petani Indonesia Dan Upaya Meningkatkan Kesejahteraannya. Jakarta: penebar Swadaya.

Aji. J. M.M dan Widodo. A. 2010. Perilaku Konsumen Pada Pembelian Beras Bermerel di Kabupaten Jember dan Faktor-Faktor Yang Mempengaruhinya. J.SEP Vol. 4. No. 3.

Aroning, R., 2008. Analisis Saluran dan Hasil margin Pemasaran Kakao di Desa Timbuseng, Kecamatan Pattalasang, Kabupaten Gowa. http://www.deptan.go.id. Diakses pada tanggal 26 November 2012.

Ariwibowo, Agus (2013). Analisis Rantai Distribusi Komoditas Padi Dan Beras di Kecamatan Pati Kabupaten Pati. Skripsi, Fakultas Ekonomi, Universitas Negeri Semarang. 
Asmarantaka, Ratna Winandi. 2014. Pemasaran Agribisnis (Agrimarketing). IPB Press: Bogor.

Dinas Pertanian Tanaman Pangan dan Hortikultura Provinsi Bali, 2021.

Sudiyono, A., 2004. Pemasaran Pertanian. Universitas Muhammadiyah Malang Press, Malang.

Syahza, Almasdi. 2003. Paradigma Baru: Pemasaran Produk Pertanian Berbasis Agribisnis. Jakarta: Fakultas Ekonomi Universitas Tarumanagara.

Tatiek, 2012. Lembaga, Saluran Pemasaran, dan Fungsi Pemasaran dalam Tataniaga Agroproduk. Universitas Brawijaya: Semarang.

Whitney, F.L. and J. Milholland. 1933. A Four year Continuation Study of A Teachers College Class. Jour. Educ. Res. 1933. Pp. 193-199. Dalam Nazir, 1985. Metode Penelitian. Ghalia Indonesia. Jakarta 